\title{
Postoperative endoleak after EVAR and effective endovascular reintervention. The case of the 64-year-old male with abdominal aortic aneurysm with concomitant common iliac artery aneurysm
}

\author{
Michał Jerzy Terpiłowski'®, Marek Iłżecki², Stanisław Przywara², \\ Barbara Terpiłowska ${ }^{3} \mathbb{D}$, Piotr Terlecki ${ }^{2}$, Tomasz Zubilewicz ${ }^{2}$ \\ 'Doctoral School, Department of Vascular Surgery and Angiology, Medical University of Lublin, Poland \\ ${ }^{2}$ Department of Vascular Surgery nad Angiology, Medical University of Lublin, Poland \\ ${ }^{3}$ Students' Scientific Society, Chair and Department of Vascular Surgery and Angiology
}

\begin{abstract}
Endovascular aneurysm repair (EVAR) is a widely accepted alternative for open surgical repair (OSR) in the treatment of an abdominal aortic aneurysm (AAA). Meta-analyses of randomized controlled trials revealed significantly lower short-term mortality after EVAR procedure than OSR. From a technical point of view, proper sizing and selection of the stent-graft is very important. Most instructions for use (IFUs) of the current endografts recommend 10-20\% oversizing concerning the preoperative aortic diameter. It can prevent endoleaks or subsequent complications such as displacement of the leg to the abdominal aneurysmal sac. In this paper, we present a case of a 64-year-old male with a history of abdominal aortic aneurysm with concomitant common iliac artery (CIA) aneurysm. The patient underwent endovascular implantation of bifurcated stent-graft with extension to the right common iliac artery. He was admitted to the Department of Vascular Surgery due to increasing pain in the right-lower abdomen. The analysis of the imaging examination and the symptoms of an increasing lower limb ischaemia caused by deformation of the stent-graft allowed deciding for an endovascular intervention involving the implantation of the iliac side branch device (IBD). Postoperative angiography confirmed the correct location of the IBD with proper blood flow. After five days the patient was discharged home.
\end{abstract}

Key words: EVAR, iliac side branch device, endoleak, common iliac artery aneurysm

Acta Angiol 202I; 27, 2: 57-60

\section{Introduction}

National health services screening programs report that $0.8 \%$ of examined men had an AAA measuring between $3.00 \mathrm{~cm}$ and $5.49 \mathrm{~cm}$ and were currently under surveillance. Less than $0.1 \%$ men had larger aneurysms - over $5.5 \mathrm{~cm}$. [I]. For more than two decades EVAR has been a valuable alternative for open surgery in the management of AAA. Over the last years, the treatment of AAA and/or iliac artery aneurysm has undergone many modifications and improvements. Complications after EVAR can be serious, and sometimes require immediate diagnosis and interventions [2]. The most common complication of stent-graft placement is endoleak [3]. Al-Juburi et al. [4] reported that endoleak was responsible for $66 \%$ of EVAR reinterventions in

Address for correspondence: Michał Jerzy Terpiłowski, Doctoral School, Department of Vascular Surgery and Angiology,

Medical University of Lublin, Staszica II, 20-08I Lublin, Poland, e-mail: michal.terpilowski@gmail.com 


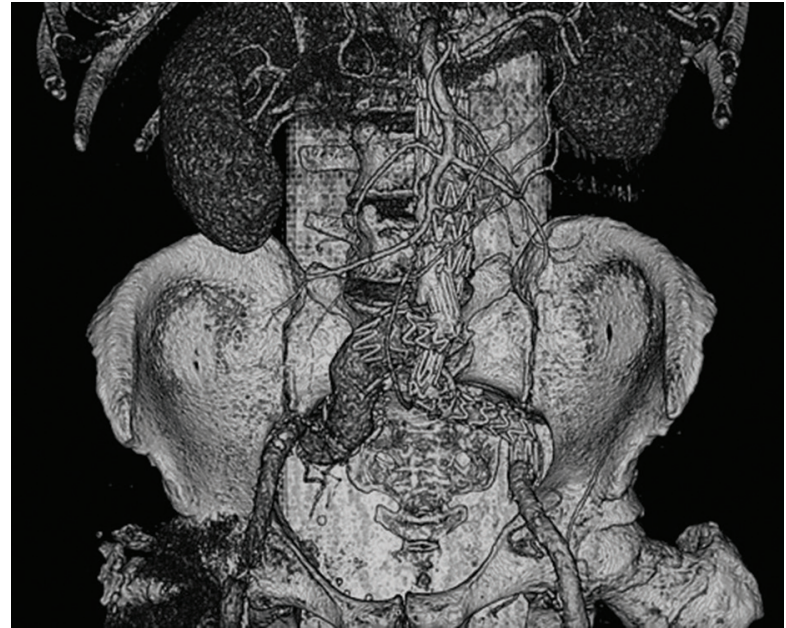

Figure I. Angio-CT showing migration of the stent-graft

their results. From a technical point of view, proper sizing and selection of the stent-graft is very important. Depending of the anatomy of AAA and involvement of iliac arteries, several options of endovascular aortoiliac repair are available including: implantation of extension to external iliac artery with optional coil embolization of hypogastric artery or implantation of iliac side branch device or iliac branch endoprosthesis (IBD/IBE).

\section{Case study}

The case of 64-year-old man with a history of chronic obstructive pulmonary disease, hypertension and right hip replacement surgery (in 2009) is presented. In 2016 patient underwent implantation of bifurcated stent-graft with extension to the right common iliac artery because of AAA - with concomitant common iliac artery (CIA) aneurysm. He was admitted to the Department of Vascular Surgery due to increasing pain in the right-lower abdomen. Preoperative workup including a computed tomography angiography (angio-CT) showed migration of the stent-graft (Fig. I). Imaging test also revealed stent-graft kinking that caused a flow restriction and lumen stenosis. Decision about treatment method was made after analysis of the imaging examination and the exacerbation of chronic lower limb ischaemia. Patient was qualified for the endovascular intervention involving the implantation of the Zenith ${ }^{\circledR}$ Branch Endovascular Graft-Iliac Bifurcation to the right external iliac artery with the branch to the right internal iliac artery. Vascular access was obtained through the left brachial artery (Fig. 2). Postoperative angiography confirmed the correct placement of the IBD with proper blood flow (Fig. 3). On the fifth day after the endovascular procedure, the patient

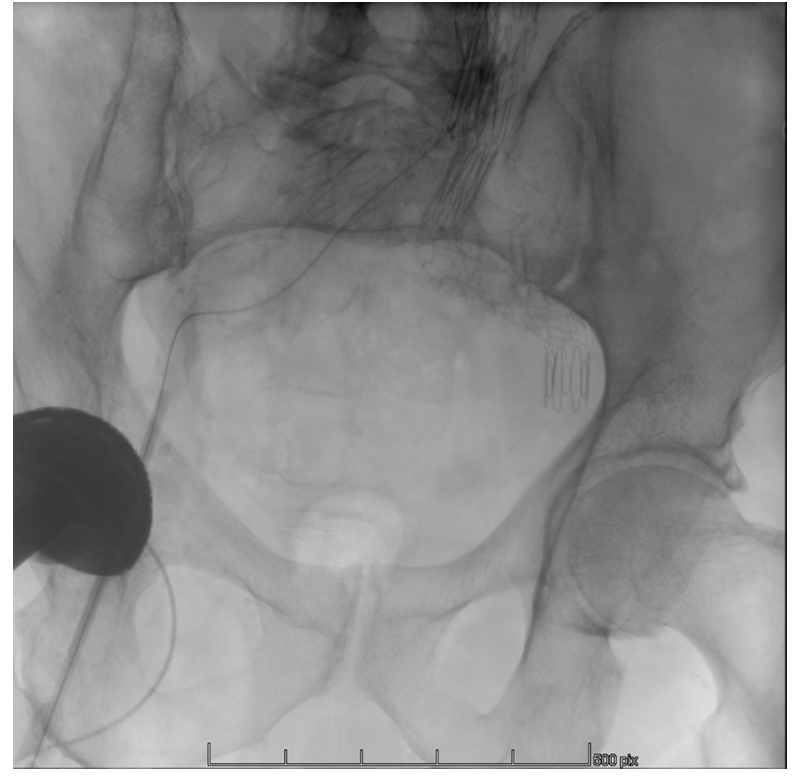

Figure 2. Catheterisation of right iliac axis

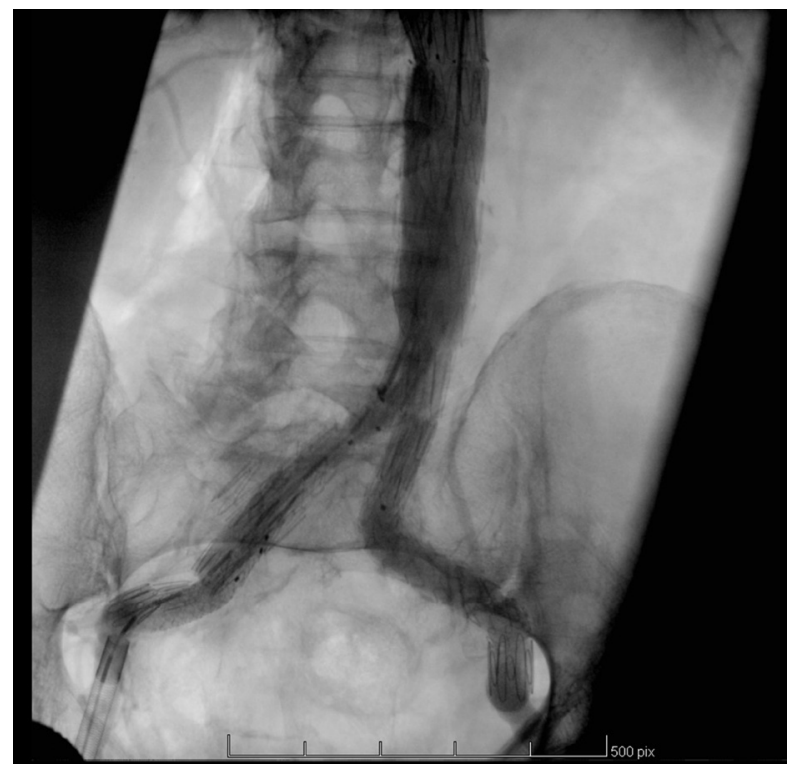

Figure 3. Angiography after implantation of IBD. Confirmation of the optimization of the blood flow and correct position of the IBD

was discharged home in good general condition with recommendations for regular controls in the outpatient vascular surgery clinic.

\section{Discussion}

Meta-analyses of randomized controlled trials comparing endovascular aneurysm repair (EVAR) with open surgical repair (OSR) revealed significantly lower short- 
term mortality after EVAR procedure than OSR [5-9]. Complication rates after EVAR reach $30 \%$ while late complications occur in $3 \%$ of cases $[10,1 \mathrm{I}]$. Moreover, systematic follow-up of patients after EVAR is equally important, what allows immediate detection and intervention in case of complications. The highest rate of the reinterventions after EVAR was reported during the first 6 months, with further reinterventions peak after 2 years. The critical factors which increase graft-related complication are: larger initial aneurysm diameter and older age of the patient [12]. Most instructions for use (IFUs) of the current endografts recommend I0-20\% oversizing for the preoperative aortic diameter [13]. Conrad et al. [15] found that AAA sac size more than $5.5 \mathrm{~cm}$ and preprocedural coil embolization of the hypogastric or inferior mesenteric artery were predictors of endoleaks requiring reintervention. In the presented case, dislocation of the right iliac extension was caused by type III of endoleak. It could be caused by the defect of the extension leg, incorrect fixation in the common iliac artery or increasing of the diameter of the AAA [16]. The methods of reintervention after stent-graft migration include: implantation of an iliac side branch device, hypogastric coiling or open repair (OR) [17]. Verzini et al. [18] revealed no significant differences in reintervention rates at one-year after IBD implantation in comparison with hypogastric artery coiling, whereas iliac endoleak in log-term follow-up was present in 19\% of patients after coiling and only in $4 \%$ of patients after IBD placement. Donas et al. [19] found that the lower invasiveness of the procedure and better intraoperative and postoperative outcomes justify the use of IBD rather than OR for patients with suitable anatomy. Moreover, the infrequent occurrence of buttock claudication and pelvic ischaemia bring a strong argument for the use of IBD.

Based on a presented case it is possible to state the following conclusions:

- Endoleaks are the most common complications after EVAR They can be successfully treated by endovascular methods.

- Implantation of IBD is an effective method of reintervention caused by the endoleak with better postoperative outcomes than OR.

\section{Conflict of interest}

None.

\section{References}

I. Crighton, E Public health screening program annual report: I April 2018 to 3I March 2019. (2020).

2. Picel AC, Kansal N. Essentials of endovascular abdominal aortic aneurysm repair imaging: postprocedure surveillance and com- plications. AJR Am J Roentgenol. 2014; 203(4): W358-W372, doi: 10.2214/AJR. 13.1 1736, indexed in Pubmed: 25247965.

3. Maleux G, Koolen M, Heye S. Complications after endovascular aneurysm repair. Semin Intervent Radiol. 2009; 26(I): 3-9, doi: 10.1055/s-0029-1208377, indexed in Pubmed: 21326525.

4. Al-jubouri M, Comerota AJ, Thakur S, et al. Reintervention after EVAR and open surgical repair of AAA: a 15 -year experience. Ann Surg. 2013; 258(4): 652-7; discussion 657, doi: 10.1097/ SLA.0000000000000157, indexed in Pubmed: 24002301.

5. Paravastu SC, Jayarajasingam R, Cottam R, et al. Endovascular repair of abdominal aortic aneurysm. Cochrane Database Syst Rev. 2014(I): CD004I78, doi: 10.1002/1465I858.CD004I78. pub2, indexed in Pubmed: 24453068.

6. Becquemin JP, Pillet JC, Lescalie F, et al. ACE trialists. A randomized controlled trial of endovascular aneurysm repair versus open surgery for abdominal aortic aneurysms in low- to moderate-risk patients. J Vasc Surg. 20II; 53(5): II67-II73.el, doi: 10.1016/j.jvs.2010.10.124, indexed in Pubmed: 21276681 .

7. Prinssen M, Verhoeven ELG, Buth J, et al. Dutch Randomized Endovascular Aneurysm Management (DREAM)Trial Group. A randomized trial comparing conventional and endovascular repair of abdominal aortic aneurysms. N Engl J Med. 2004; 35।(16): 1607-1618, doi: 10.1056/NEJMoa042002, indexed in Pubmed: 15483279.

8. Patel R, Sweeting M, Powell J, et al. Endovascular versus open repair of abdominal aortic aneurysm in 15-years' follow-up of the UK endovascular aneurysm repair trial I (EVAR trial I): a randomised controlled trial. The Lancet. 2016; 388(10058): 2366-2374, doi: 10.1016/s0140-6736(16)31135-7.

9. Lederle F, Freischlag J, Kyriakides T, et al. Long-Term Comparison of Endovascular and Open Repair of Abdominal Aortic Aneurysm. New England Journal of Medicine. 2012; 367(21): 1988-1997, doi: 10.1056/nejmoa 207481.

10. d'Audiffret A, Desgranges P, Kobeiter DH, et al. Follow-up evaluation of endoluminally treated abdominal aortic aneurysms with duplex ultrasonography: validation with computed tomography. J Vasc Surg. 200I; 33(I): 42-50, doi: 10.1067/ mva.200I.II 2215, indexed in Pubmed: III 37922.

II. Kranokpiraksa P, Kaufman JA. Follow-up of endovascular aneurysm repair: plain radiography, ultrasound, CT/CT angiography, MR imaging/MR angiography, or what? J Vasc Interv Radiol. 2008; 19 (6 Suppl): S27-S36, doi: 10.1016/j.jvir.2008.03.009, indexed in Pubmed: 18502384.

12. Brown LC, Greenhalgh RM, Powell JT, et al. EVAR Trial Participants. Use of baseline factors to predict complications and reinterventions after endovascular repair of abdominal aortic aneurysm. Br J Surg. 2010; 97(8): 1207-1217, doi: 10.1002/ bjs.71 04, indexed in Pubmed: 20602502.

13. van Prehn J, Schlösser FJV, Muhs BE, et al. Oversizing of aortic stent grafts for abdominal aneurysm repair: a systematic review of the benefits and risks. Eur J Vasc Endovasc Surg. 2009; 38(I): 42-53, doi: 10.1016/j.ejvs.2009.03.025, indexed in Pubmed: 19428273.

14. https://www.cookmedical.com/products/ndo_aaamain_ webds/.

15. Conrad MF, Adams AB, Guest JM, et al. Secondary intervention after endovascular abdominal aortic aneurysm repair. Ann Surg. 2009; 250(3): 383-389, doi: 10.1097/SLA.0b0 I 3e3 I8I b365bd, indexed in Pubmed: 19652592. 
16. Patel SR, Allen C, Grima MJ, et al. A Systematic Review of Predictors of Reintervention After EVAR: Guidance for Risk-Stratified Surveillance. Vasc Endovascular Surg. 2017; 5I(6): 417-428, doi: 10.1/77/15385744/77/2648, indexed in Pubmed: 28656809.

17. Bendermacher BLW, Stokmans R, Cuypers PhW, et al. EVAR reintervention management strategies in contemporary practice. J Cardiovasc Surg (Torino). 20 2 2; 53(4): 4 I I-4 I8, indexed in Pubmed: 22854520.
18. Verzini F, Parlani G, Romano L, et al. Endovascular treatment of iliac aneurysm: Concurrent comparison of side branch endograft versus hypogastric exclusion. J Vasc Surg. 2009; 49(5): I|54-I|6I, doi: 10.1016/j.jvs.2008.1I.100, indexed in Pubmed: 19394544

19. Donas KP, Torsello G, Pitoulias GA, et al. Surgical versus endovascular repair by iliac branch device of aneurysms involving the iliac bifurcation. J Vasc Surg. 20II; 53(5): 1223-1229, doi: 10.1016/j.jvs.2010.10.121, indexed in Pubmed: 21276683. 